\title{
Structural and optical properties evolution of 'fused' multilayer Nano PbS thin films deposited by chemical bath deposition
}

\author{
Ali M. Mous*, Selma M. Al-Jawad, Suad M. Kadhim Al-Shammari \\ Department of Applied Science, University of Technology, Baghdad, Iraq \\ *E-mail address: alzuhery51@yahoo.com
}

\begin{abstract}
Here, we report the unusual behavior shown by the $\mathrm{PbS}$ samples prepared using a multilayer deposition approach by chemical solution deposition method. Thin samples were prepared by depositing several films at different deposition conditions on glass substrates. X-ray diffraction showed that final multilayer samples showed a peculiar variation. Even when they showed well defined structure the intensities of the peaks do not correspond to those of the initial films.
\end{abstract}

Keywords: Nano PbS; fused multilayer; XRD; CBD

\section{INTRODUCTION}

The current trend in solar cell fabrication usually employs a multi hetrojunction structure to extend the spectral sensitivity of cells to near-infrared wavelengths, which contain as much as half of the energy of the solar spectrum [1,2].

The requirement of a high efficiency and reduced mismatching coupling among the layers can be satisfied by growing the Nano layers in a sequential band gap decreasing [3-8]. $\mathrm{PbS}$ is a narrow band gap semiconductor of $0.27 \mathrm{eV}(\mathrm{T}=293 \mathrm{~K})$, which crystallizes in a face center cubic, and showing higher band gap in the Nano state [9].

Many workers have been investigated the physical properties of the PbS Nano thin films deposited at various conditions.

Although extensive works on synthesis and characterization of Nanocrystalline $\mathrm{PbS}$ have already been reported $[10,11]$, no works on multi layers structural of these materials in Nanocrystalline form are done. To our knowledge, chemical aqueous syntheses of fused' multilayer Nano PbS thin films deposited by chemical bath deposition have not yet been reported.

\section{EXPERIMENTS}

For multilayer $\mathrm{PbS}$ structures, Films were coated in a sequential manner with an intermediate drying step after coating each layer, using different deposition conditions lead to the structures, $\mathrm{PbS}_{1} / \mathrm{PbS}_{2} /$ glass, $\mathrm{PbS}_{1} / \mathrm{PbS}_{2} / \mathrm{PbS}_{3} /$ glass and $\mathrm{PbS}_{1} / \mathrm{PbS}_{2} / \mathrm{PbS}_{3} / \mathrm{PbS}_{4} /$ glass, 
with $\mathrm{PbS}_{1}$ largest band gap film. The thickness of the $\mathrm{PbS}$ films is chosen to be sufficiently thick to decrease transmission through the film but thin enough so that the films are in Nano structure. $\mathrm{PbS}$ thin films were deposited using a $\mathrm{CBD}$ deposition technique [4].lead acetate the source of $\mathrm{Pb}$ ions, and thiourea $\left(\mathrm{SC}\left(\mathrm{NH}_{2}\right)_{2}\right)$ the source of $\mathrm{S}$ ions. It is important to control $\mathrm{pH}$ of these solutions since the $\mathrm{PbS}$ precipitates are stable only in the $\mathrm{pH}$ range 10 to 13 [5]. $\mathrm{pH}$ control and chelating is achieved using sodium hydroxide for $\mathrm{PbS}$. The thickness of $\mathrm{PbS}$ increases with increasing concentration of $\mathrm{S}$ ions in solution and with increasing deposition time and bath temperature. During deposition different conditions was employed as shown in Table 1, which shows the deposition conditions of the samples constituent films, while Table 2 shows the sequence of films deposition. To explore various physical properties of these materials, two characterization methods, including X-ray diffraction and optical transmission have been applied. The spectral characteristics of the different multi layers samples were evaluated using a PerkinElmer UV-VIS spectrometer. Film thickness obtained from the optical measurements. The crystallinity and microstructure of the films were characterized by $\mathrm{x}$-ray diffraction (XRD, Bruker D5) with $\mathrm{CuK} \alpha$ radiation. Electrical studies of as deposited films carried out using Hall measurement system (Ecopia, HMS-300) at room temperature with varying the current.

Table 1. Deposition condition of the films.

\begin{tabular}{|c|c|}
\hline Film & Deposition conditions \\
\hline F1 & $\mathrm{d}=82 \mathrm{~nm}, \mathrm{RT}, \mathrm{pH}=10.5, \mathrm{t}=15 \mathrm{~min} .$, \\
\hline F2 & $\mathrm{d}=70 \mathrm{~nm}, 10^{\circ} \mathrm{C}, \mathrm{pH}=11.6, \mathrm{t}=30 \mathrm{~min} .$, \\
\hline F3 & $\mathrm{D}=70 \mathrm{~nm}, \mathrm{RT}, \mathrm{pH}=11.6, \mathrm{t}=45 \mathrm{~min}$, \\
\hline F4 & $\mathrm{d}=123 \mathrm{~nm}, \mathrm{RT}, \mathrm{pH}=12, \mathrm{t}=60 \mathrm{~min}$, \\
\hline F5 & $\mathrm{D}=162 \mathrm{~nm}, \mathrm{RT}, \mathrm{pH}=11.6, \mathrm{t}=90 \mathrm{~min}$, \\
\hline F6 & $\mathrm{d}=166 \mathrm{~nm}, 70^{\circ} \mathrm{C}, \mathrm{pH}=11.6, \mathrm{t}=120 \mathrm{~min}$, \\
\hline
\end{tabular}


Table 2. Sequence of films deposition and thickness.

\begin{tabular}{|c|c|c|c|}
\hline sample & Sequence of deposition & d measured (nm) & d calculated (nm) \\
\hline Sample 1 & F1 / F2 / Glass & 151 & 152 \\
\hline Sample 2 & F3 / F4 / Glass & 200 & 193 \\
\hline Sample 3 & F5 / F6 / glass & 328 & 328 \\
\hline Sample 4 & F3 / F4 / F5 / Glass & 379 & 355 \\
\hline Sample 5 & F3 / F4 / F5 / F 6 /Glass & 533 & 521 \\
\hline
\end{tabular}

\section{2. Substrate Preparation}

Substrate used for deposition $\mathrm{PbS}$ is borosilicate glass slides, which were first cleaned in distilled water in order to remove the impurities and residuals from their surfaces, followed by rinsing in chromic acid (for one day), to introduce functional groups called nucleation and / or epitaxial centers, which formed the basis for the thin films growth [3]. Then the samples were washed repeatedly in deionized water, and finally placed in ultrasonic agitation with distilled water for $15 \mathrm{~min}$ then dried [12-22].

\section{3. Solution Preparation and Deposition of Nano PbS Films}

The starting materials in the preparation of lead sulfate $(\mathrm{PbS})$ includes lead acetate $[\mathrm{Pb}$ $\left.\left(\mathrm{CH}_{3} \mathrm{COO}\right)_{2} \cdot 2 \mathrm{H}_{2} \mathrm{O}\right]$, Potisum hydroxide $(\mathrm{KOH})$, thiourea $\left[\left(\mathrm{NH}_{2}\right)_{2} \cdot \mathrm{CS}\right]$, triethanolamine TEA and distilled water. The lead acetate is the source of cation $\left(\mathrm{Pb}^{2+}\right)$ and thiourea is the source of anion $\left(\mathrm{S}^{2-}\right)$. $\mathrm{KOH}$ is used to provide an alkaline medium $(10-12.5 \mathrm{pH})$.

The deposition steps start with the immersion of the glass substrate is vertically in a beaker $(100 \mathrm{ml})$ containing the reaction mixture. The solution was stirred with a magnetic stirrer type (MSH 300). The PH measured with PH meter type (BIBBY). The substrates were then taken out after a suitable time, they were washed with distilled water and ultrasonic agitation to remove the porous lead sulfide over layer. These films after drying are used as substrates for the deposition of multi layer $\mathrm{PbS}-\mathrm{PbS}$ films. PbS films are kept vertically on the walls of the container with the deposition mixture for $\mathrm{Pb}$.

\section{3. Thickness Measurement}

Film thickness measured by optical interferometer method. the light beam reflection from thin film surface and substrate bottom. He - Ne Laser $(0.632 \mu \mathrm{m})$ is used and the thickness is determined using the formula:

$$
d=\frac{\Delta x}{x} \cdot \frac{\lambda}{2}
$$

where $\mathrm{x}$ is fringe width, $\Delta \mathrm{x}$ is the distance between two fringes and $\lambda$ is the wave. 


\section{4. Structure Measurement}

To determine the nature of the growth films and the structural characteristics of single and multilayer Nano PbS films, $\mathrm{X}$ - ray diffraction has been done and compared with the ASTM cards, using Philips PW $1840 \mathrm{X}$ - ray diffractometer of $\lambda=1.54 \AA$ from $\mathrm{Cu}-\mathrm{K} \alpha$. The average grain size (GS) of the polycrystalline material can be calculated from the $\mathrm{X}$ - ray spectrum by means of Full Width at Half Maximum (FWHM) method (Debye-Scherrer relation) [6]:

$$
\mathrm{GS}=\mathrm{A} \lambda / \Delta \beta \cos \theta
$$

where $\Delta \beta$ is the full - width at half maximum of the XRD peak appearing at the diffraction angle $\theta$, A the shape factor, the value of which depends on the crystalline shape, and generally it is 1 .

\section{5. Optical Measurements}

Cecile CE 7200 Spectrophotometer was used to record the optical transmission of Nano $\mathrm{PbS} /$ glass thin films for the range $(375-1100 \mathrm{~nm})$. The data from transmission spectrum can be used in the calculation of the absorption coefficient $(\alpha)$ for PbS films, according to the following equation [7]:

$$
\alpha=\frac{1}{d} \ln \frac{1}{T}
$$

where $\mathrm{d}$ is the thickness of thin film, and $\mathrm{T}$ is the transmission, To determine the optical gap of the investigated films the following relation is.

\section{RESULTS AND DISCUSSION}

\section{1. Growth kinematics}

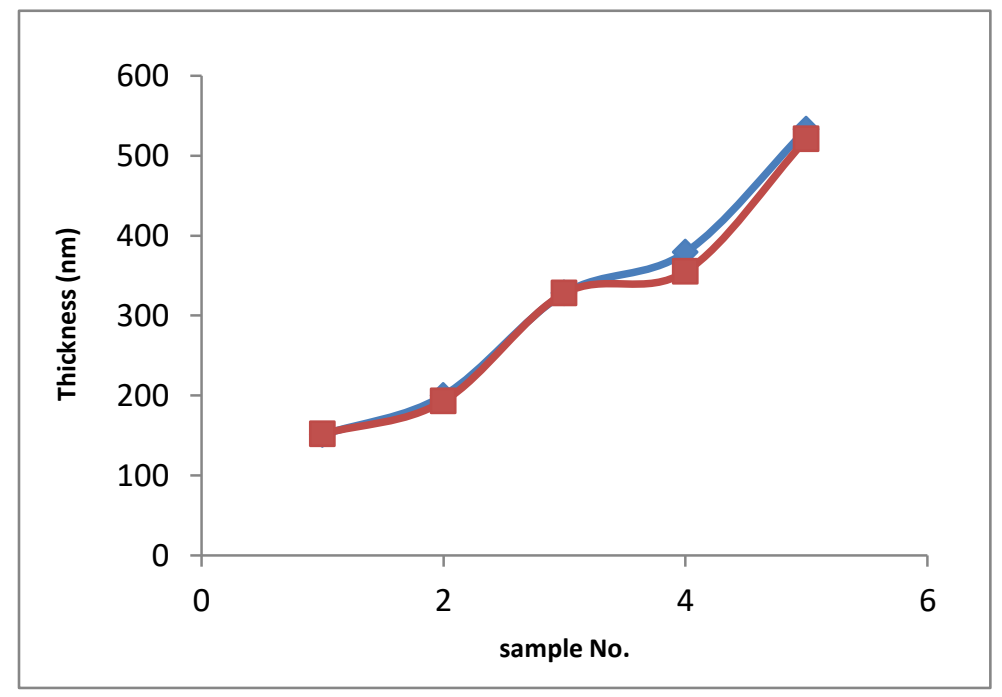

Figure 1. Measured and calculated thickness of multi layered films. 
The multi layers $\mathrm{PbS}$ samples were obtained with different two, three and four layers structure to discern the influence of different structures on the samples properties. Growth kinetic curves have shown in Fig. 1.

Indicate that final deposited multilayer structure having thickness equal to the sum of the constituent films thicknesses.

\section{2. Structure Properties}

Fig. 2 shows the XRD patterns of all multi layers samples, such multi layers exhibit texture components which vary with the deposition conditions of the constituent films. The $2 \theta$ values of diffraction peaks observed around $26.5^{\circ}, 30.8^{\circ}, 43.9^{\circ}, 52.18^{\circ}$ and $53^{\circ}$; these peaks correspond to reflections from (111), (200), (220), and (311) and (222) planes of cubic PbS respectively.

The reflections from these planes have previously been reported [8-10]. For the different multi layers samples, the trend in intensity of their peaks follows that of the standard $\mathrm{PbS}$ powder. The height of (200) peak relative to other reflections signified the extent of caxis orientation and film structural quality. Due to the matching of the individual multi layer sample peak positions with the standard ICCD XRD data for pure PbS ,and the significant change in the peaks profiles, this suggests the intermixing of the second deposited layer with the first under lying layer and the multi layer $\mathrm{PbS}$ films retain the same bulk crystalline structure and high c-axis orientation.

In XRD the reflection peak intensity is function of film thickness and the degree of crystallization. Hence, the intensity per unit thickness will illuminate the influence of the degree of crystallization. To gain some insight on the crystallization degree of our multi layers we compare in Table 3 samples $(1,2,3)$ with two deposited films having the higher crystallization degree comparing to the three and four deposited films samples.

Intensity of plane (200) increased by a factor of seven in sample 3 comparing to the same plane intensity of sample with four deposited layers, and that of reflection plane (111) increased by more than four times, and the same increasing with plane (220). In all fused multi layer a change from (111) to (200) observed and the intensity ratio of plans (111) and (220) with that of plane (222) are far from the standard.

The change from (111) to (200) in terms of competing contributions of surface and strain energy producing an orientational cross-over phenomenon (11) at small film thicknesses growth is determined by the surface energy and a (200) preferred orientation is observed. At thicker film the strain contribution increased and the (111) orientation is detected. also the samples thickness have insignificant effect on these ratio the values enter parentheses\}.

From Table 4 it is clear that the intensity of the main peaks increased in the multi layer samples relative to the calculated intensity (the summation of the main peaks intensity of the constituent films) except that of sample 5 (four layers) which shows a decreasing in intensities.

This increasing in the intensities could be attributed to the incomplete separation between the multi layers making it easy for the $\mathrm{Pb}^{2+}$ and $\mathrm{S}^{2-}$ ions to diffuse among the sub layers during the subsequent deposition process and leads to a 'fused' multilayer configuration. That is, the deposited $\mathrm{PbS}$ films do react with each other during the deposition of successive layers. 

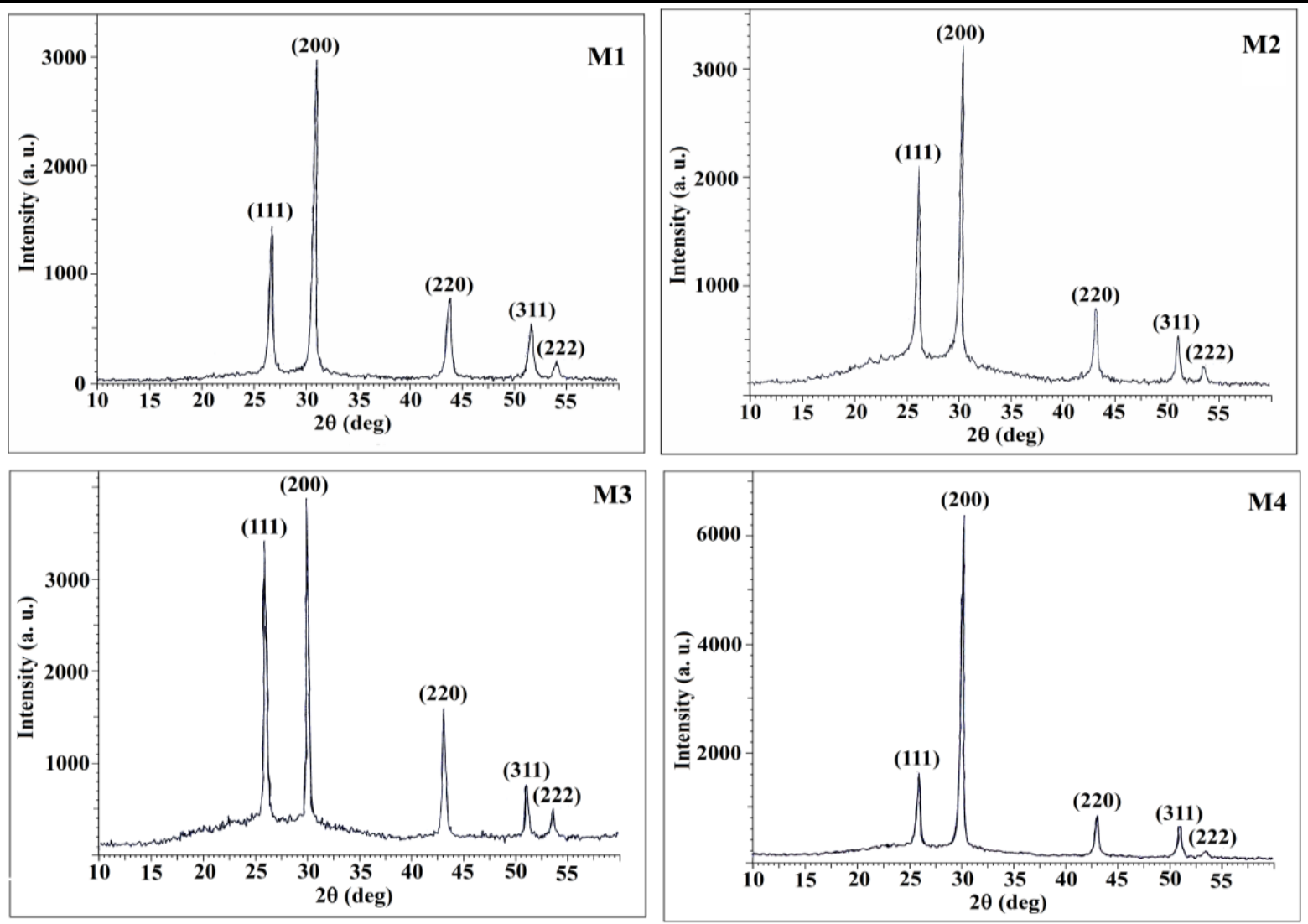

Figure 2. X-ray patterns for number layer of nano $\mathrm{PbS}$ films for different time $\left(\mathrm{T}=30^{\circ} \mathrm{C}, \mathrm{pH}=11.6\right.$, $\mathrm{MPb}=0.25 \mathrm{M}, \mathrm{MSc}=0.5 \mathrm{M})$.

Table 3. The intensities of diffraction peaks of $\mathrm{PbS}$ samples.

\begin{tabular}{|c|c|c|c|}
\hline Sample & Thickness (nm) & I 111 / I 200 & I 220/ I 200 \\
\hline Sample 1 & 151 & $0.31(0.347)$ & $0.25(0.3)$ \\
\hline Sample 2 & 200 & $0.645(0.58)$ & $0.24(0.264)$ \\
\hline Sample 3 & 328 & $0.243(0.24)$ & $0.13(0.14)$ \\
\hline Sample 4 & 379 & $0.357(0.353)$ & $0.19(0.189)$ \\
\hline Sample 5 & 533 & $0.757(0.81)$ & $0.312 \mathrm{C}(0.334)$ \\
\hline
\end{tabular}




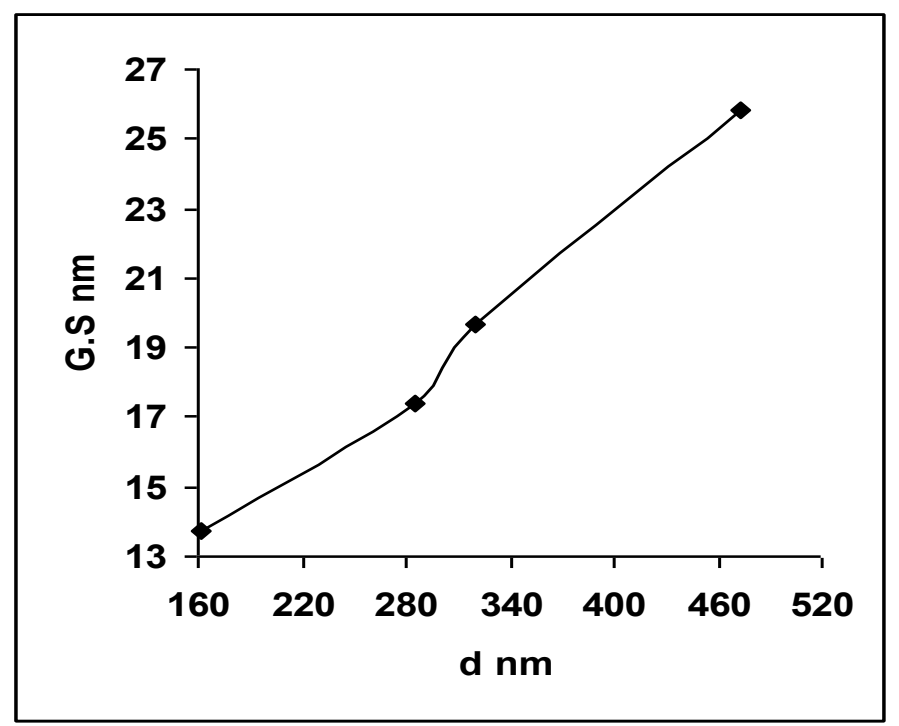

Fig. 3. Average grain size with thickness for multilayer films.

Table 4. The experimental and calculated intensities of diffraction peaks of $\mathrm{PbS}$ samples.

\begin{tabular}{|c|c|c|c|c|c|c|c|c|c|c|c|c|}
\hline Sample & plane & F1 & F2 & F3 & F4 & F5 & F6 & $I(\exp )$ & I (calc) & Iexp / Ical & $\varepsilon^{*} 10^{-2}$ & $\begin{array}{c}\mathrm{S}\left(\mathrm{N} / \mathbf{m}^{2}\right)^{*} \\
10^{9}\end{array}$ \\
\hline \multirow[b]{3}{*}{1} & 111 & 675 & 460 & - & - & - & - & 560 & 1135 & 0.5 & 1.45 & 1.8 \\
\hline & 200 & 625 & 435 & - & - & - & - & 1615 & 1060 & 1.52 & & \\
\hline & 202 & 280 & - & - & - & - & - & - & - & - & & \\
\hline \multirow{3}{*}{$\mathrm{F} 1 / \mathrm{F} 2 / \mathrm{G}$} & 220 & - & - & - & - & - & - & 380 & 280 & 1.357 & & \\
\hline & 311 & - & - & - & - & - & - & 265 & - & - & 0.178 & 2.147 \\
\hline & 222 & - & - & - & - & - & - & - & - & - & & \\
\hline \multirow{6}{*}{ F3 / F4 /G } & 111 & - & - & 600 & 825 & - & - & 2070 & 1425 & 1.45 & & \\
\hline & 200 & - & - & 50 & 870 & - & - & 3560 & 920 & 3.89 & & \\
\hline & 202 & - & - & - & - & - & - & - & - & - & 2.29 & -1.25 \\
\hline & 220 & - & - & - & 400 & - & - & 940 & - & 940 & & \\
\hline & 311 & - & - & - & 290 & - & - & 560 & - & - & & \\
\hline & 222 & - & - & - & - & - & - & 300 & - & - & & \\
\hline \multirow[b]{3}{*}{3} & 111 & - & - & - & - & 850 & 900 & 1720 & 1750 & 0.98 & 1.79 & 2.23 \\
\hline & 200 & - & - & - & - & 900 & 975 & 7125 & 1875 & 3.8 & & \\
\hline & 202 & - & - & - & - & 500 & - & - & 500 & - & & \\
\hline \multirow{3}{*}{$\mathrm{F} 5 / \mathrm{F} 6 / \mathrm{G}$} & 220 & - & - & - & - & 340 & 400 & 1000 & 740 & 1.35 & & \\
\hline & 311 & - & - & - & - & 230 & 250 & - & 480 & - & 1.67 & \\
\hline & 222 & - & - & - & - & - & - & - & - & - & & \\
\hline \multirow{6}{*}{$\mathrm{F} 3 / \mathrm{F}$} & 111 & - & - & 600 & 825 & 850 & - & 1500 & 2275 & 0.66 & & \\
\hline & 200 & - & - & 500 & 870 & 900 & - & 4240 & 2270 & 1.87 & & \\
\hline & 202 & - & - & - & 400 & 340 & - & - & - & - & & \\
\hline & 220 & - & - & - & & & - & 800 & 740 & 1.08 & & \\
\hline & 311 & - & - & -- & 290 & 230 & - & 600 & 520 & 1.15 & & \\
\hline & 222 & - & - & - & - & - & - & 260 & - & - & & \\
\hline
\end{tabular}




\begin{tabular}{|c|c|c|c|c|c|c|c|c|c|c|c|c|}
\hline \multirow{5}{*}{5} & 111 & - & - & 600 & 825 & 850 & 900 & 1060 & 3175 & 0.98 & & \\
\cline { 2 - 14 } & 200 & - & - & 500 & 870 & 900 & 975 & 1310 & 3245 & 2.5 & & \\
\cline { 2 - 14 } & 202 & - & - & - & - & 500 & - & - & 500 & & & \\
\cline { 2 - 13 } \\
F3/F4/F5/G & 220 & - & - & - & 400 & 340 & 400 & 438 & 1140 & 0.38 & & \\
\cline { 2 - 12 } & 311 & - & - & - & 290 & 230 & 250 & 280 & 770 & 0.36 & & \\
\cline { 2 - 11 } & 222 & - & - & - & -- & - & - & 800 & - & - & & \\
\hline
\end{tabular}

\section{3. Optical Energy Gap}

The energy gap values depends in general on the films crystal structure, the arrangement and distribution of atoms in the crystal lattice, also it is affected by crystal regularity. The plot of $(\alpha h v)^{2}$ versus photon energy for different deposition parameters as shown in Fig. 4 . The linear dependence of $(\alpha h v)^{2}$ with (hv) indicates direct band gap. The energy gap (Eg) value is calculated by extrapolation of the linear straight line as shown in Fig. 5. For one layer and multilayers. For one layer film, the band gap decreases with the increase in the film thickness until $150 \mathrm{~nm}$ where a sharp falls takes place. For multilayers film the band gap decreased with layers thickness but with much sharping falls.
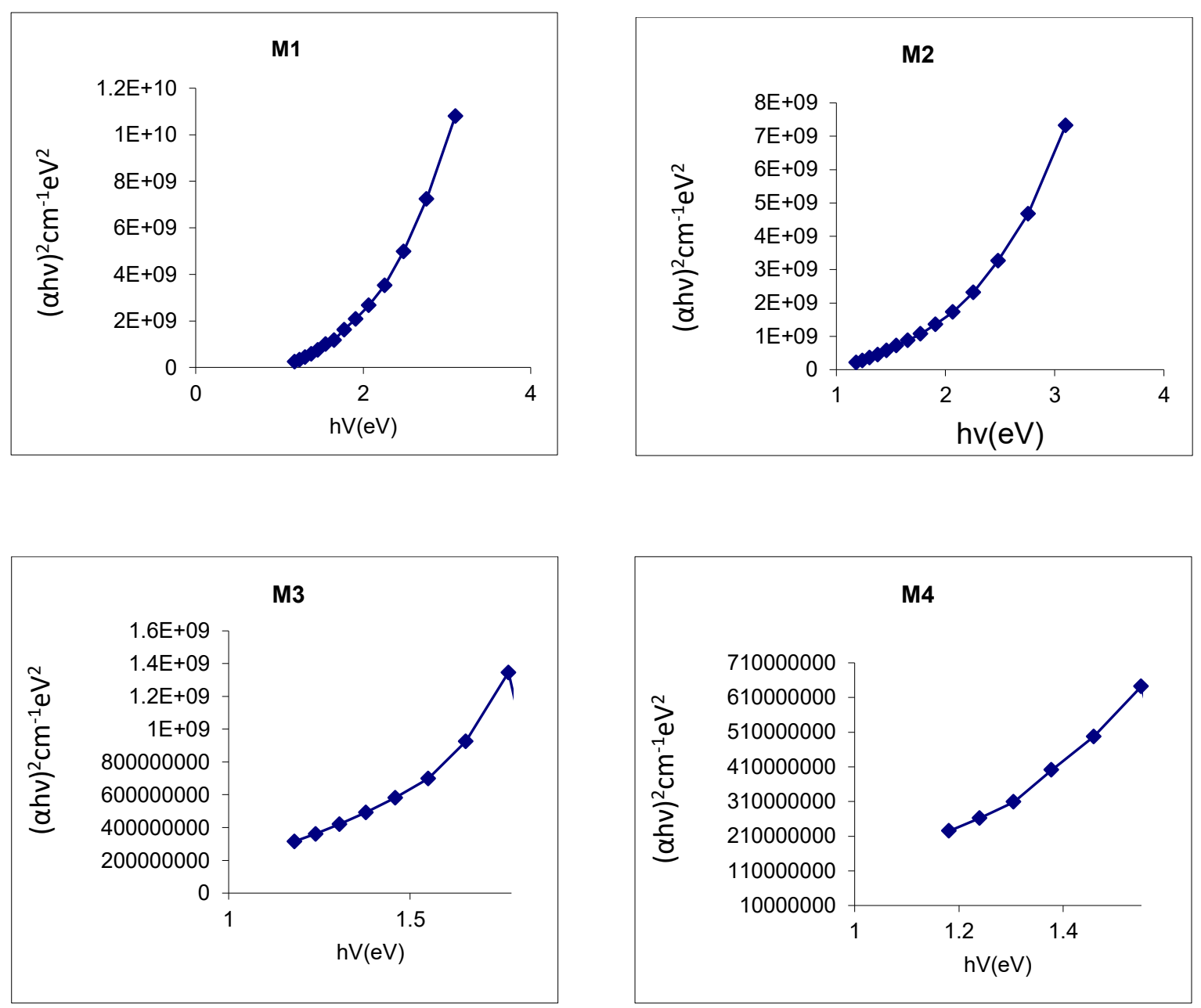

Fig. 4. A plots of $(\alpha h v)^{2}$ verses (hv)of PbS nano films for different deposition parameters. 

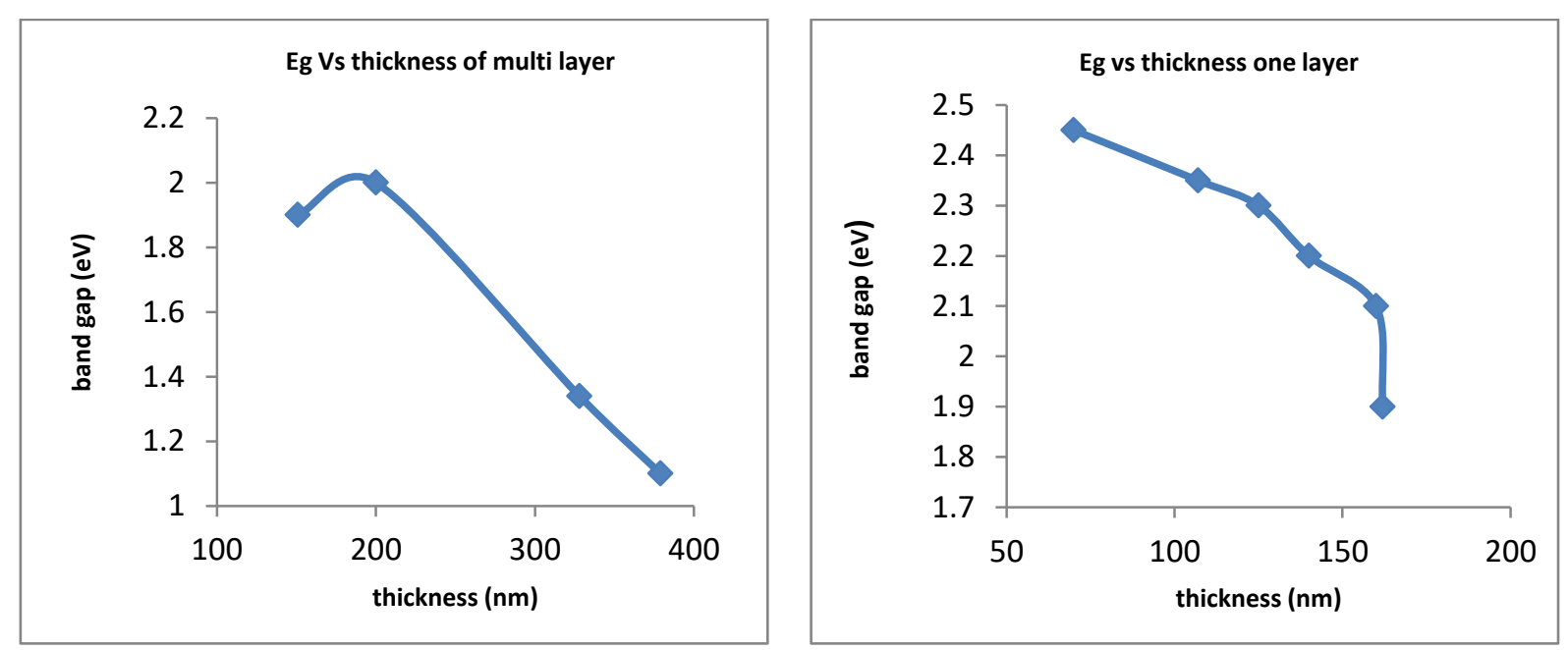

Fig. 5. Band gaps of $\mathrm{PbS}$ nano films for one and multilayes.

\section{CONCLUSIONS}

There are two important conclusions derived from this work. First the successively deposited $\mathrm{PbS}$ films do react with each other during the deposition of successive layers and result in a 'fused' multilayer configuration, although the growth of the previous layer has been completed.

The trend in intensity of fused multilayer peaks follows that of the standard $\mathrm{PbS}$ powder, also the samples thickness have insignificant effect on the main peaks ratio. At the same time, the average grain size increases with increasing number of deposited layers Second the orientational cross-over phenomenon could be attributed to competing contributions of surface and strain energy.

\section{References}

[1] Ni Zhao, Tim P. Osedach, Liang-Yi Chang, Scott M. Geyer, Darcy Wagner, Magdalena T. Binda, Alexi C. Arango, Moungi G. Bawendi, Vladimir Bulovic, ACS Nano 4(7) (2010) 3743-3752.

[2] M. A. Contreras, J. Tuttle, A. Gabor, A. Tennant, K. Ramanathan, S. Asher, A. Franz, J. Keane, L. Wang, R. Noufi, Solar Energy Materials and Solar Cells 41-42 (1996) 231-246.

[3] Lingyun Bai, Mingsheng Li, Jun Wang Junhuai Xiang Shuwang Duo, Wenkui Li, J Mater Sci: Mater Electron (2009) 20 (2009) 319-322.

[4] Christiana B. Honsberg, Allen M. Barnett, Douglas Kirkpatrick, IEEE ( 2006) 2565-2568.

[5] R. Pathak, S. Joshi, P. Kotak, Multi Scale Modeling of Nano Enable Solar cell With Implementation on an HPC Setup; Third International Conference on Power Systems, Kharagpur, India, December 27-29 (2009) 1-6. 
[6] B. D. Cullity, S. R. Stock, "Elements of X - Ray Diffraction", Third edition, PrenticeHall in the United States of America, 2001.7.

K. Szendrei, W. Gomulya, M. Yarema, W. Heiss, M. A. Loi, Applied Physics Letters 97 (2010) 203501-1-3.

[7] S. M. Sze, Physics of Semiconductor Devices, Second edition, Jon Wiley and Sons, New York, 1981.

[8] A. U. Ubale, A. R. Junghare, N. A. Wadibhasme, A. S. Daryapurkar, R. B. Bankar, V. S. Sangawar, Turk. J. Phys. 31 (2007) 279-286.

[9] Y. Hou, H. Kondoh, T. Ohta, J. Crystal Growth \& Design 9 (2009) 3120-3123.

[10] Li-Zhang, Liangbao-Yang, J. Cryst. Res. Technol. 43(10) (2008) 1026-1029.

[11] S. Ikeda, J. Palleau, J. Torres, B. Chenevier, N. Bourhila, R. Madar, J. Appl. Phys. 86(4) (1999) 2300-2306.

[12] Nadir Fadhil Habubi, Sami Salmann Chiad, Saad Farhan Oboudi, Ziad Abdulahad Toma, International Letters of Chemistry, Physics and Astronomy 4 (2013) 1-8.

[13] Saad F. Oboudi, Nadir F. Habubi, Ghuson H. Mohamed, Sami S. Chiad, International Letters of Chemistry, Physics and Astronomy 8(1) (2013) 78-86.

[14] Sujan Kumar Das, Jahid M. M. Islam, Monirul Hasan, Humayun Kabir, Md. Abdul Gafur, Enamul Hoque, Mubarak A. Khan, International Letters of Chemistry, Physics and Astronomy 10(1) (2013) 90-101.

[15] J. A. Najim, J. M. Rozaiq, International Letters of Chemistry, Physics and Astronomy 10(2) (2013) 137-150.

[16] Majid H. Hassouni, Khudheir A. Mishjil, Sami S. Chiad, Nadir F. Habubi, International Letters of Chemistry, Physics and Astronomy 11 (2013) 26-37.

[17] C. Indira Priyadharsini, A. Prakasam, P. M. Anbarasan, International Letters of Chemistry, Physics and Astronomy 12 (2013) 82-93.

[18] Salam Amir Yousif, Jenan Mohamed Abass, International Letters of Chemistry, Physics and Astronomy 13 (2013) 90-102.

[19] M. M. Ismael, International Letters of Chemistry, Physics and Astronomy 14 (2013) 1-9.

[20] Harish Kumar, Renu Rani, International Letters of Chemistry, Physics and Astronomy 14 (2013) 26-36.

[21] Narender Budhiraja, Ashwani Sharma, Sanjay Kumar, Anupreet Kaur, N. V. Unikrishnan, International Letters of Chemistry, Physics and Astronomy 14 (2013) 69-79.

[22] Narender Budhiraja, Ashwani Sharma, Sanjay Dahiya, Rajesh Parmar, Viji Vidyadharan, International Letters of Chemistry, Physics and Astronomy 14 (2013) 80-88. 